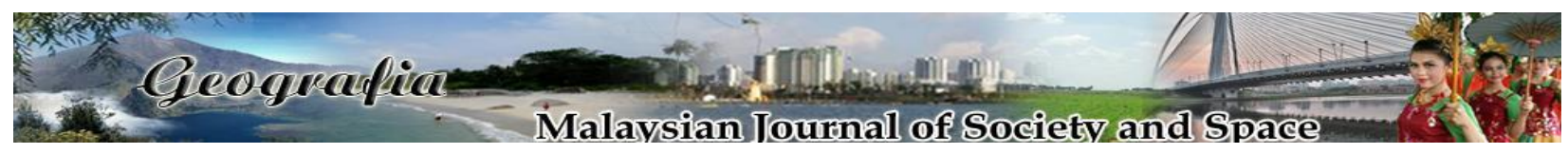

\title{
The nexus of time poverty and well-being of women from poor households: A Malaysian Indian case scenario
}

\author{
Nithiya Guna Saigaran, Premalatha Karupiah \\ School of Social Sciences, Universiti Sains Malaysia, Penang, Malaysia \\ Correspondence: Premalatha Karupiah (email: prema@usm.my)
}

Received: 01 October 2020; Accepted: 24 November 2020; Published: 29 November 2020

\begin{abstract}
Time autonomy is a core component in measuring the well-being of humans. The interrelation of time and well-being explains the autonomy one holds towards their time and improves their wellbeing. Scholars have noted that gendered aspects of well-being are always reflected through time poverty. Time autonomy is not always equal for men and women due to the interference of gender complexities in a household. In traditional societies, men's time is often dedicated to their role as breadwinners while women's time is often allocated for multiple roles (i.e. caregiver, mother and wife) in the household. Studies have shown that women's time allocation is always dedicated to their unpaid roles, which add value for the household members but often reduces their own personal well-being. Poor women have been identified as a group greatly affected by time poverty, which pushes them away from attaining well-being. This study intends to show the spectrum of time poverty experiences of Malaysian Indian women which constraints them from attaining physical and mental well-being. Data was gathered through in-depth interviews with twelve Indian women from B40 households in Sungai Petani and Kulim, Kedah, Malaysia. The findings of this study revealed that excessive weight of household chores, performing multiple roles simultaneously and minimal investment towards personal development as the three important themes. Using the themes and narration of poor Indian women, time poverty and its effects on well-being were explored in this study.
\end{abstract}

Keywords: B40 household, Malaysian tamil women, time scarcity, well-being

\section{Introduction}

Time poverty is defined as the shortage of time allocation to do the required set of activities that causes one to not be able to spend time to perform desired and preferred activities (Kalenkoski \& Hamrick, 2013; Williams, Masuda, \& Tallis, 2016; Wodon \& Bardasi, 2006). Time poverty is often identified as a phenomenon that commonly happens in poor households. Time poverty is a phenomenon that appears to be one of the most worrying issue in marginalized communities, 
especially among poor women. The high occurrence of the incidence of time poverty is related to gender inequality and persists in the form of women's roles, responsibilities and power relationship in their households (Abdourahman, 2010). Time poverty is related to the women's social class (Zilanawala, 2013). Thus, women from the lower socioeconomic class (poor households) are more likely to have high occurrence of time poverty compared to women from higher socioeconomic class (non-poor households). Women are more likely to experience time poverty due to the unequal burden of unpaid work between men and women in the household. Hence, poor women are considered more susceptible to time poverty compared to men and nonpoor women. Since women are more likely to experience time poverty, they are more vulnerable to this impoverishment which affects their well-being.

Well-being is defined as a prominent state an individual can achieve via the available resources in one's household (McIntyre \& Rondeau, 2013). In poor households, other than income deficiency, women experience time poverty due to the heavy burden of household roles which affects the well-being of poor women (McIntyre \& Rondeau, 2013). The study explores time poverty and well-being of Malaysian Indian women from B40 (bottom 40) households by focusing on their everyday experiences. This paper sheds light on the interconnection between time poverty and well-being. This interconnection is crucial because time is a significant and limited resource that determines women's possession of personal time, paid (employment) and unpaid work in the household. In other words, time scarcity could make women's well-being unattainable. Statistics have shown that Indians from the poor households in Malaysia, categorized as B40 group are often employed in lower skilled jobs, have lower educational levels, and have less wealth (Mathiaparam, 2019). Indian households in Malaysia are much influenced by patriarchal values and systems where women are seen in a subordinate position in the household and men are seen as the breadwinner. In Malaysia, poor Indian women's presence in the development is invisible because their roles and responsibilities are mostly dedicated to their households and many of them participate in non-formal work sectors. Literature review shows that very few studies in Malaysia have focused on the issue of time poverty particularly among the minority or marginalized community in Malaysia.

\section{Literature review}

Time is an important resource for human development. Time is identified as a limited resource. The well-being of the individuals is rooted strongly on their time autonomy. Time autonomy is defined as the potential of an individual in having power in allocating and managing his/her time (Robeyns, 2003). However, time is not equally available to men and women due to gender complexities in a household. A number of studies have acknowledged that division of labor ruled and constructed time possession of men and women in a household (Kroska, 2003; Ning \& Karubi, 2018; Poduval \& Poduval, 2009). While men are socialized to invest their time in productive paid roles in the public sphere, women are expected to embrace multiple unpaid roles in the domestic sphere. This evidently shows that, women tend to spend more time on tasks that have been assigned to them and they have scant time in pursuing activities that would enrich their personal development. Numerous scholars have termed these two setbacks in terms of time as time poverty (Abdourahman, 2010; Kalenkoski \& Hamrick, 2013; Williams, Masuda, \& Tallis, 2016; Wodon \& Bardasi, 2006). This time deficiency is more likely to occur among women from socially disadvantaged households (Zilanawala, 2013). Many scholars 
acknowledged that the notion of time poverty has challenged the traditional view of poverty, which merely focused on material resources (Kalenkoski \& Hamrick, 2013; Walker, 2013; Zilanawala, 2013). This is because the time perspective has the potential to unravel the underlying gender complexities in terms of autonomy, allocation and expenditure of men and women. Time is a valuable yet limited resource available to marginalized women to overcome their impoverishment by involving themselves in the economic activities like their male counterparts. However, due to their subordinated position poor women do not have the autonomy over their time use which affects their well-being (McIntyre \& Rondeau, 2013). Hence, this study intends to shed light on how women's well-being is influenced by time poverty by analyzing the experiences among Indian women from B40 households.

\section{Methods}

\section{Study design}

This study employed a retrospective study design for data collection. The participants' information, linked to their experiences of time poverty and well-being were gathered. Based on this information, the researcher explored the participants' time poverty and its effect on their well-being, particularly their physical and mental well-being. The retrospective study design was employed for this study since the time poverty incidence has already occurred at the time of the study. Through the employment of in-depth interviews, poor Indian women's experiences in terms of time poverty and well-being were explored.

\section{a. Sampling procedure and participants of the study}

A purposive sampling method was employed to select twelve participants for the in-depth interviews. Selection of the new participants ended once the data saturation was attained. Participants were recruited from B40 households with a mean household income of RM 2928 or below in Kedah, Malaysia. All the interviews were conducted in the participants' home. The participants' profile, demography, personal time and unpaid household work are presented in Table 1.

All the participants were selected from two locations in Kedah: Sungai Petani and Kulim. The participants identified Tamil as their mother tongue and were between the ages of 35 to 48 years old. They were interviewed about their time management and time allocation in order to gain insights into their time poverty experiences. Upon attaining their informed consent, interviews were conducted mainly in Tamil. 
Table 1. Participant's profile, personal time and unpaid household work

\begin{tabular}{|c|c|c|c|c|c|c|c|c|}
\hline No & Pseudonym & Age & $\begin{array}{c}\text { Marital } \\
\text { Status }\end{array}$ & $\begin{array}{l}\text { Working } \\
\text { Status }\end{array}$ & $\begin{array}{c}\text { Personal } \\
\text { Time* }\end{array}$ & $\begin{array}{c}\text { Average } \\
\text { Personal } \\
\text { time } \\
\text { (hours) } \\
\end{array}$ & $\begin{array}{c}\text { Unpaid } \\
\text { household } \\
\text { work** }\end{array}$ & $\begin{array}{c}\text { Average } \\
\text { unpaid } \\
\text { household } \\
\text { work (hours) }\end{array}$ \\
\hline 1 & Informant 1 & 46 & Married & Cleaner & 1 hour & \multirow{12}{*}{$\begin{array}{l}\quad 21 \text { hours } \\
\quad \div 12 \\
=1.75 \\
\text { hours }\end{array}$} & 15 hours & \multirow{12}{*}{$\begin{array}{c}165 \text { hours } \\
\div 12 \\
=13.75 \text { hours }\end{array}$} \\
\hline 2 & Informant 2 & 38 & Married & Housemaid & 2 hour & & 14 hours & \\
\hline 3 & Informant 3 & 42 & Married & Nanny & 1 hour & & 12 hours & \\
\hline 4 & Informant 4 & 40 & Married & Cleaner & 1 hour & & 15 hours & \\
\hline 5 & Informant 5 & 43 & Married & Housewife & 2.5 hours & & 17 hours & \\
\hline 6 & Informant 6 & 44 & Married & Nanny & 3 hours & & 12 hours & \\
\hline 7 & Informant 7 & 42 & Married & Housewife & 2.5 hours & & 14 hours & \\
\hline 8 & Informant 8 & 45 & Married & Housewife & 0.5 hours & & 18 hours & \\
\hline 9 & Informant 9 & 40 & Married & Helper & 1 hour & & 11 hours & \\
\hline 10 & Informant 10 & 36 & Divorced & Cleaner & 1.5 hours & & 12 hours & \\
\hline 11 & Informant 11 & 40 & Married & Clerk & 3 hours & & 13 hours & \\
\hline 12 & Informant 12 & 43 & Married & Clerk & 2 hours & & 12 hours & \\
\hline
\end{tabular}

\section{b. Interview Process}

The interview process included open ended questions that were designed to gather the time poverty experiences. The participants were requested to share the information on their time allocation and how it affects their well-being, especially in terms of physical health and mental health. Questions regarding time management and time allocation were posed to the participants. In terms of physical well-being, (e.g. How did you spend time to improve your physical health? How many hours in a day did you spend time to make efforts to maintain your health? How many hours do you spend for your paid and unpaid work?). These questions intend to probe information regarding participants' time management and the state of their mental and physical well-being. Consent of the participants was obtained before the interview session. Interview sessions lasted for about an hour.

\section{c. Data coding and analysis}

The interviews were recorded and transcribed in Tamil. Then, the transcriptions were translated to English. The transcriptions were checked for accuracy. Each recording was transcribed and was about ten to fourteen pages and were coded in a few stages. The transcripts reflected the women's experiences revolving around time poverty and well-being. Three themes related to time poverty and well-being were identified during the analysis. Analysis was conducted with the use of a qualitative data analysis software, NVivo 11. All participants were assigned pseudonyms to maintain confidentiality of their identities. 


\section{Results and discussion}

Three themes were identified in the analysis: excessive weight of household roles, handling multiple roles, and minimal time investment to personal development. The themes are presented in the following section.

\section{Theme 1: Excessive weight of household chores}

One important theme identified among the participants was excessive weight of household roles. Household chores constitute all types of work revolving around the household i.e. taking care of children, cooking, cleaning, washing clothes and housekeeping which is often categorized as unpaid labor (Kroska, 2003). When asked regarding time allocation in the household, all participants agreed that they were managing excessive amount of household chores. This was further confirmed through time expenditure where participants were found to spend an average of 13.75 hours a day (more than half a day), for unpaid work in the household (refer to Table 1). This is due to the gendered division of the labor system that exists in poor households. With such division of labor, men and women were responsible for two different spheres; private and public sphere (Sourabh, 2008). While women were assigned to work mostly in the household, which is known as the private sphere, men were expected to focus on the public sphere which is employment. However, the segregation of labor does not yield equal validation for men and women. Gender inequality arises when women is forced to be in charge of household for unpaid chores while men were expected to take up paid work outside the household. Informant 2 explained how the segregation of labor in a household took place.

"Before I got married, I was expected to be responsible in managing all the housework...after I got married, the situation remained the same...I needed to take care of all the household work...It's been 10 years I am doing the same work over and over again...my husband is just going to work, he just needs to do one job, which is his technician work...we never interfered in each other's' work." (Informant 2, age 38)

The division of labor became the basis of gender socialization of men and women (Ning $\&$ Karubi, 2018). While men were raised to focus on their employment, women were trained to perform household chores and manage a household in the future (Kroska, 2003; Poduval \& Poduval, 2009). The process of gender socialization emphasizes the need for women to dedicate their time in providing services in the household by doing housework or taking care of other members of the family. Performing various services to family members is seen as an important part of the expression of femininity. Thus, paid work becomes a secondary option for women or it is something that has to be pursued after fulfilling their roles in the household.

"As a woman I need to be focused on the household tasks; cooking, cleaning and washing clothes. From the time I wake up, I have to do all the things on my own. As a woman in the family, the running of the household depends on these tasks, my time should be spent on it...working outside from home is not very important" (Informant 5, age 40)

Gender becomes the significant determinant for time poverty (Arora, 2015). The above response from Informant 5, shows that in poor households, women's time was fully occupied 
with domestic tasks that have been assigned to them. The household chores have two major setbacks: it is unpaid and consumes long hours without a specific time frame. Nine out of the twelve participants admitted that they spent many hours to complete their household chores because they were housewives. Informant 6 explained about her household chores.

"Speaking about housework, it was never ending story in my house... I need to keep doing it all the time, there's no time for me to rest...sometimes till midnight. My husband is always busy with his work and even after he comes home after work, he doesn't help with anything... For him, housework needs to be done my women" (Informant 6, aged 44)

From the above explanation, it is clear that women's household work did not have a fixed time frame and no value was attached to it. Regarded as feminine work, women are expected to do household chores, which is beneficial for the household members, particularly their husband and children. Their time is designed in such a way that they continuously serve the interests of their household members with the household work. For instance, when they cook, the household members received the food for their daily productivity. However, these women do not receive the benefit from the unlimited household chores. Their experiences show elements of time deficiency but they often express this as being something 'normal'. It is understood as something that women have done for generations, hence is seen as part of being a woman. Informant 10 shared her experience on this aspect.

"I have no time for myself... which means my 24 hours in a day is for my family... actually I did not regret this.... I am happy that I am able to contribute to the family...women's lives have always been like this right; my great grandmother, my grandmother...I have also observed my mother... so it applies the same to me...spend our time for family...spending time for yourself is not really a significant one..." (Informant 10, age 36)

The response of Informant 10 proved the fact that the time poverty experience was normalized in the life of poor Indian because they were socialized to accept this as part of their identity. Hence, poor Indian women understand that the time allocation for the household is their fate and compulsory in their lives. Their loyalty towards their husband is measured based on the time dedicated for household work. Therefore, they did not think that allocating time for themselves was important. As a result, lack of time for themselves i.e. the experience of time poverty brought negative impacts to their well-being. Ten out of twelve participants admitted this fact and explained about the impact of excessive household work on themselves. Informant 1 shared her feelings.

"Sometimes I feel so exhausted because of housework, especially, the cleaning work. It's too much too handle...I have less sleep because of housework. I often have body aches here and...sometimes I have migraine, the severe one..." (Informant 1, age 46)

"Nowadays I can't do much due to the pain in my knee... Walking fast has become very difficult for me. Now I feel I could not handle it anymore; 
washing, brushing the floor, cleaning the drainage for hours. The non-stop house chores had made me so tired..." (Informant 7, age 42)

From the response of Informant 1 and Informant 7, the well-being of women was greatly affected and they were suffering because of the time deficiency they experienced due to their household chores. The time women spent to do the unpaid work had compromised their health quality (Santana, Loomis, \& Newman, 2001). Repeating the same workload for years, with no proper breaks, and lack of sleep, puts them in a position that jeopardizes their capability to attain individual well-being, as explained by Informant 10, Informant 6, Informant 5 and Informant 2. This impacts their well-being causing them to live with various emotional and physical issues with no financial benefit provided for the unpaid work that they have done.

\section{Theme 2: Performing multiple roles simultaneously}

Another significant theme from the experiences of the participants is that performing multiple roles in the household affects their well-being. Women in poor households had to perform multiple roles. When they were young, they performed similar roles as a female child. Upon marriage, they began embracing the roles of a housewife, a mother and a caretaker. These roles were designed to serve the interest of the patriarchal system and for positioning men into the authoritative position (Kandiyoti, 1988; Sultana, 2011). Traditionally, women's worth is measured based on their time contribution to their household roles (Chowdhury \& Patnaik, 2013). This was confirmed through this study where all the participants in this study unanimously agreed that they were performing multiple roles at the same time and it was an important part of being a woman. Below is the explanation from Informant 3.

"My husband goes to work at 7 in the morning...He is working as a mechanic in town...I wake up at 5.40 in the morning. So before he wakes up, I need to prepare everything for him, his clothes to wear... prepare breakfast, lunchbox and some snacks for him in the evening. Not only that, I need to make sure the bath pail is full of water, towel is ready and bathroom is clean, if not I will be scolded by him..." (Informant 3, age 42)

In most societies, women's time is not owned by them (Abdourahman, 2010). Others, particularly their husbands, utilize women's time. From the above explanation by Informant 3, she was expected to prepare everything to ensure that her husband is able to go out to work. Her failure to fulfill this expectation often results in punishment, in terms of being scolded or receiving negative remarks. In order to make sure her husband's productive paid work goes well, she herself needs to do much unpaid work using her own time. This is further confirmed by scholars that women's time is always strongly associated to their husband's interest and they have the authority to manage women's time spent in the household (Abdourahman, 2010). Women's subordinated position supports the interest of the growth of a patriarchal family (Abdourahman, 2010; Chowdhury \& Patnaik, 2013; Kandiyoti, 1988; Sawant, 2016). The subordination of women in the Indian society is perpetuated through the mother's role construction (Chowdhury \& Patnaik, 2013). After being a wife, women need to play the role as a mother since it is regarded as the completion of femininity as a whole (Chowdhury \& Patnaik, 2013; Desai \& Thakkar, 2001). Informant 10 explained her role as a mother: 
"I am a single mother...it's been 7 years I was divorced. The kids are with me...I have to take care of everything on my own. Before I go to work, I have to prepare everything for them; iron their clothes, pack lunches etc... After returning from work, I need to clean the house, cook dinner for them.... and listen to their non-stop complaints about the school" (Informant 10, age 47)

Motherhood is depicted as the main component that consumes the time of women (Cerrato \& Cifre, 2018; Ning \& Karubi, 2018). The intensity and depth of the duties and responsibilities as a mother is far more significant compared to other roles of women (Jabeen et al., 2020; Ning \& Karubi, 2018). Similar to Informant 10, women in poor families need to play an intense mother's role in the household. However, being a mother in a socioeconomically disadvantaged household means that the probability to experience time poverty has also doubled up. In this study, poor Indian women's time poverty experiences revealed that the intensity of motherhood increased when their partners were absent from the breadwinner's role. Three out of twelve participants have admitted the struggle in managing their time to fulfill a mother and a breadwinner role at the same time due to their partner's absence (due to separation, divorce or death). Therefore, single mothers face the pressure to embrace the breadwinner's role for the family. The burden of the workload is bulked up and makes women experience more time deficiency. This study further revealed that, other than embracing the roles of wives, mothers and caretakers, women are expected to look after the elders in the household. Since the Indian household is constructed based on patriarchal values, Indian women are held responsible to look after the elder members of the husband's family (Chowdhury \& Patnaik, 2013; Desai \& Thakkar, 2001). Informant 5 shared:

"After my husband goes to work, I will get everything prepared in my household. After that I need to look after my in laws, they are staying with me.... They are quite elderly people, aged in their 90's... They need help with everything.... Their diabetic food, clothing, and I need to bring them for their monthly checkup.... I need to take care of on my own. I have been doing this for 15 years...together with my husband, I'm married to them too (Informant 5, age 43)

Informant 5 revealed the intensity of the caretaker role of women in socially disadvantaged households. The non-poor households often have an option to outsource caring tasks by hiring a nanny or housemaids but this is not possible in poor households due to the limited household income. These women have the pressure to conform to the traditional expectation of femininity by fulfilling the responsibility of being a good daughter-in-law by taking care of their parents-in-law. Ignoring or defying these responsibilities comes with negative consequences such as defamation and isolation from the husband's families, which might jeopardize their status as an married woman. In addition, it could mean that they had lost their dependency in terms of emotional, social and financial support from their husbands, which could escalate their vulnerability towards impoverishment. Participants in this study felt that, the multiple roles they played in the household and the burden of household work had impacted their mental and physical health. They struggled in embracing the multiple roles simultaneously. Informant 9 explained: 
"My mind is like all around the place on my way walking back home. When my husband is back from work, I need to cook fresh food. I need to be there standing and serving him the food. At the same time, I need to look after my children, who will be there nagging me to teach them to do their homework, feed them... Sometimes I'll be just shouting at them....I also need to take care of my father in law, need to do everything for him, give him food and clothes...Everyday, after my work finishes, on my way back home, thinking about what needs to be done after I reach, I feel like I can't breathe anymore. I feel so nervous thinking about waking up every day" (Informant 9, age 40)

Personal time in the form of leisure is compulsory for an individual to maintain a healthy life (Zilanawala, 2014, 2013). Nine out of the twelve participants felt that they were facing immense stress playing roles as a wife, mother and caretaker and satisfying the needs of the household members. As a result of the pressure of managing multiple roles, they shared their experiences of anxiety and felt that they were experiencing depression. Other studies have confirmed that anxiety and depression are common in poor households (Santana et al., 2001). As a consequence, women like Informant 4 felt that the burden of multiple roles in the household had affected her mental health and this jeopardizes her productivity at her work place.

"I cannot concentrate at work, my supervisor always scolds me for not doing this, doing that... I have no time to sleep well before going to work, it's been so many years already since I had a very deep sleep...At work, I overslept during my lunch breaks which annoyed my supervisor...There were a few times he deducted my salary" (Informant 4, age 40)

Performing multiple roles means that poor Indian women have no time autonomy in their households. This is similar to Moser's (1980) concept of "triple roles". In this framework, she had highlighted that women are most often occupied with roles in the sphere of production, reproduction and community affairs which reveals the unequal division of labor between men and women (Ludgate, 2016). Surrounded by multiple household roles that needs to be performed simultaneously, their time management was always decided primarily by the patriarchal system. Disproportionate time was dedicated for the well-being of their household members as explained by Informant 3, Informant 10 and Informant 5. In ensuring the well-being of their family members, majority of the poor Indian women, like Informant 9, experienced time scarcity which affected their well-being.

\section{Theme 3: Minimal time investment towards personal development}

In this study, poor Indian women revealed that time deficiency affects women's well-being due their minimal investment towards personal development. Personal development is significantly lower for the women due to their workload in their households. In this study, the average hour women spent as their personal time was 1.75 hours excluding their sleeping hours, (refer to Table 1). This exposed the time scarcity of poor women in doing activities that they desired such as for their leisure, pursuing other goals, hobbies, listening to music or reading. An individual's personal development depends on the choices and freedom that he or she has in their household (McIntyre \& Rondeau, 2013; Sen, 2001). Women often have restrictions on the things they are 
"allowed" or "not allowed" to do compared to their male counterparts in poor households (Sen, 2017). Looking from this perspective, the men have enormous space to enhance personal development compared to the women. Poor Indian women have various barriers in creating this freedom of space due to the time deficiency they experienced in the household. Time is a significant resource that determines what people are "able to do" and "able to be" (Sen, 2001). However, majority of the women in this study did not have the freedom to spend time on activities that were pleasurable to them. Informant 8 explained:

"All these years, I have never groomed myself, like really, I never had done it. When I was young, I always like to dress myself up and go out...but after marriage I have never had the time to get dressed up, make up and go somewhere" (Informant 8, age 45)

Time poverty happens when one has no time to fulfill his/her wishes and desires and is forced to spend time to do things that has become his/her tasks (Abdourahman, 2010; Arora, 2015). Similar to Informant 8 , nine out of the twelve participants mentioned that they rarely had time to attain and achieve their desires. Sen (2017) mentioned that resources are crucial to create a life one values and time is an important resource to create a life that one values. The real valuation of the individual time is rooted on how far an individual invests in their lives with the activities that are beneficial to themselves. Informant 12 expressed her feelings about her inability to utilize her time for her personal development by pursuing her desires.

"I always wanted to have my own business doing flower garlands for pooja and religious events... when I got married, I told my husband about this and he permitted me after so many attempts of convincing him...but it did not last long. I needed to stop the business because every time customers came to order flower garlands, he was angry, he was jealous and suspicious...it's my dream to own a business... but till now it still remains a dream" (Informant 12, aged 43)

Experiences of Informant 12 show the restrictions and barriers that a woman faced to pursue her personal development, which has the potential to contribute to her well-being in future. Eight out of the twelve participants admitted that they possessed special talents and skills that could not be pursued or enhanced due to their household duties and engagement with the household members. This explains that the occurrence of time poverty in the household has a great impact in affecting their individual capabilities (Sen, 2001). Like Informant 12, the capabilities in the form of talents and skills, which have the potential to give freedom to women are not encouraged in patriarchal households. This is due to the poor women's time was expected to be invested into the well-being of their husband and their family members. Likewise, women's time is controlled by others in the household, mainly the husband. The lack of time autonomy forces the woman to neglect her personal development. The restriction and interruption to invest their time into their personal development affect their self-esteem, which may make them feel stressed and anxious about their lives. Informant 12 shared her feelings:

"I feel so depressed when I was not allowed to continue my flower garland business... I have done so much for all the people around me, my husband and 
my children...sacrificed my time for their benefits, but when it comes to me, no one seems to be interested in it...the business means a lot to me" (Informant 12, age 43)

In this study, depression, as described by the participants and anxiety were experienced by five out of twelve participants. They were unable to improve their well-being because they did not have the autonomy over how they spent their time. They were unable to allocate time for their personal development. Their narrations reflect the impact of minimal investment of their time towards their well-being.

\section{Significance of the Study}

This study intends to shed light on socioeconomically disadvantaged B40 households in terms of their gendered time poverty which affects the well-being of women living in these households. It gives some insights into how poor Indian women experience time poverty and how it affects their well-being. It sheds light on the complexity of the marginalization experienced by Malaysian Indian women. Most poverty related studies ignored marginalization issues of Indians in comparison to other ethnic groups in Malaysia.

\section{Conclusion}

This paper draws attention on time poverty experiences that affect the well-being of women in poor households. Excessive weight of household chores, performing multiple roles simultaneously and minimal investment towards personal development were identified as the themes showed connection between time poverty and well-being of poor Indian women. Time poverty is a complex issue and is vastly occurring in poor households due to the patriarchal system. Narration of time poverty experiences revealed that the whole process of establishment of time poverty was gendered.

\section{References}

Abdourahman, O. I. (2010). Time Poverty: A contributor to women's poverty? The African Statistic Journal, 11(11), 287-307. https://doi.org/10.1093/acprof:oso/9780199468256. 003.0008

Arora, D. (2015). Gender differences in time-poverty in rural Mozambique. Review of Social Economy, 73(2), 196-221. https://doi.org/10.1080/00346764.2015.1035909

Cerrato, J., \& Cifre, E. (2018). Gender inequality in household chores and work-family conflict. Frontiers in Psychology, 9(1330), 1-11. https://doi.org/10.3389/fpsyg.2018.01330

Chowdhury, A., \& Patnaik, M. M. (2013). Understanding Indian family life: The gender perspectives. International Journal of Multidisciplinary Management Studies, 3(7), 58-67.

Desai, N., \& Thakkar, U. (2001). Women in Indian society. New Delhi, India: National Book Trust.

Drago, R., Black, D., \& Wooden, M. (2005). Female breadwinner families: Their existence, 
persistence and sources. Journal of Sociology, 41(4), 343-362. https://doi.org/10.1177/ 1440783305058465

Gammage, S. (2011). Conditional cash transfers and time poverty: An example from Guatemala. Cuadragésima Sexta Reunión de La Mesa Directiva de La Conferencia Regional Sobre La Mujer de América Latina y El Caribe, 1-17. Santiago: International Labour Organization.

Jabeen, S., Haq, S., Jameel, A., Hussain, A., Asif, M., Hwang, J., \& Jabeen, A. (2020). Impacts of rural women's traditional economic activities on household economy: Changing economic contributions through empowered women in rural Pakistan. Sustainability, 12(7), 1-23. https://doi.org/10.3390/su12072731

Kalenkoski, C. M., \& Hamrick, K. S. (2013). Time poverty thresholds in the USA. In A. Michalos (Ed.), Health Promotion:Adolecent Well Being (pp. 6650-6653). https://doi.org/ 10.1007/978-94-007-0753-5_3704

Kandiyoti, D. (1988). Bargaining with patriarchy. Gender \& Society, 2(3), 274-290.

Kroska, A. (2003). Investigating gender differences in the meaning of household chores and child care. Journal of Marriage and Family, 65(2), 456-473. https://doi.org/10.1111/ j.1741-3737.2003.00456.x

Ludgate, N. (2016). Moser gender analysis framework. In United States Agency for International Development (USAID). Retrieved from www.ndi.org/files/Guide to Gender Analysis Frameworks.pdf.

Mathiaparam, B. (2019). Indian youths in Penang: Opportunities, challenges and solutions. Penang, Malaysia.

McIntyre, L., \& Rondeau, K. (2013). Understanding the aspirations of ultra-poor women in Bangladesh can enhance well-being and target development efforts. International Journal of Well-being, 3(1), 82-97. https://doi.org/10.5502/ijw.v3i1.5

Ning, E. C. Y., \& Karubi, N. P. (2018). Gender Socialisation and its relation to women's work and family conflict. Trends in Undergraduate Research, 1(1), 11-18. https://doi.org/ 10.33736/tur. 1179.2018

Poduval, J., \& Poduval, M. (2009). Working mothers: How much working, how much mothers, and where is the womanhood? Mens Sana Monographs, 7(1), 63-79. https://doi.org/ 10.4103/0973-1229.41799.

Robeyns, I. (2003). Sen's Capability Approach and gender inequality: Selecting relevant capabilities. Feminist Economics, 9(2-3), 61-92.

Rubiano, Matulevich, E. C., \& Viollaz, M. (2019). Gender differences in time use: Allocating time between the market and the household ( Policy Research Working Paper No. 8981). Retrieved from World Bank Group.

Santana, V. S., Loomis, D. P., \& Newman, B. (2001). Housework, paid work and psychiatric symptoms*. Revista de Saúde Pública, 35(1), 16-22. https://doi.org/10.1590/S003489102001000100003

Sawant, T. S. (2016). Place of the woman in Indian society: A brief review. Journal of Humanities and Social Science, 21(9), 21-25. https://doi.org/10.9790/0837-2109082125

Sen, A. (2001). Development as freedom. Oxford University Press.

Sen, A. (2017). Collective choice and social welfare: Expanded edition. United Kingdom: Penguin Press.

Sourabh, N. C. (2008). The culture of women's housework: A case study of Bihar, India (Academic dissertation). University of Helsinki.

Sultana, A. (2011). Patriarchy and women's subordination: A theoretical analysis. The Arts 
Faculty Journal, 1-18.

Walker, J. (2013). Time poverty, gender and well-being:Lessons from the Kyrgyz Swedish health programme. Development in Practice, 23(1), 57-68. https://doi.org/10.1080/ 09614524.2013.751357

Williams, J. R., Masuda, Y. J., \& Tallis, H. (2016). A measure whose time has come: Formalizing time poverty. Social Indicators Research, 128(1), 265-283. https://doi.org/ $10.1007 / \mathrm{s} 11205-015-1029-\mathrm{z}$

Wodon, Q., \& Bardasi, E. (2006). Measuring time poverty and analyzing its determinants: Concepts and application to Guinea (World Bank Working Paper No. 4). In Gender, Time use, and Poverty in Sub-Saharan Africa. Retrieved from World Bank Group.

Zilanawala, A. (2013). Women's time poverty: Differences by family structure, employment, and gender ideology ( $\mathrm{PhD}$ dissertation). Columbia University.

Zilanawala, A. (2014). Women's time poverty and family structure: Differences by parenthood and employment. Journal of Family Issues, 37(3), 369-392. https://doi.org/10.1177/ $0192513 X 14542432$ 